\title{
Costs of satellite camera threaten to push Europe out of the picture
}

Munich. With less than four months to go before the contract for the Rosetta mission to the comet Wirtanen is due to be put out to tender by the European Space Agency (ESA), the question of who will control the closest and most spectacular images of a comet yet produced has still to be resolved.

A special meeting of representatives from ESA and its science programme committee (SPC) tomorrow (8 March) is expected to agree to a new 'announcement of opportunities' by ESA, inviting proposals to build a camera for Rosetta, the third of four 'cornerstone' missions being planned by ESA. But there is concern that, if non-ESA states provide substantial funding, the European agency may be deprived of much of the public credit for the mission.

Money is at the root of the problem. A sophisticated imaging system, able both to carry out a range of scientific analyses and to provide high-resolution photographs suitable for public relations purposes, was originally expected to be designed and paid for by a consortium of ESA member states, led by Germany. But these countries have now decided that they can no longer afford it.

Rosetta will meet up with the comet Wirtanen in deep space and accompany it for two years as the comet moves towards the Sun, to determine changes in both its nucleus and surface during the approach.

As with all ESA science missions, the costs of the launch and the spacecraft are paid for directly by the agency. But the instruments for the scientific payload, whose composition - apart from an imaging system - was agreed last month, are developed by outside scientists and paid for by national space and research agencies.

The proposal for an imaging system, called Osiris, capable of obtaining images in the visible, ultraviolet and near-infrared wavelengths, was given high scientific and technical ratings by Rosetta's independent peer review committee last autumn.

But the proposal was not given a top priority rating. Some claim this may have been because of hopes at the time - since dashed by the agency's financial difficulties - that ESA would provide a camera covering visible wavelengths, or perhaps because the navigational system, which controls the spacecraft's orbit around the comet through simple imaging, might be upgraded to take high-resolution colour photographs.

Furthermore, much of the infrared and ultraviolet range covered by the proposed imaging system is already covered by other instruments on the payload. In these circumstances, Germany, which had already agreed to contribute significantly to other instruments with higher priority ratings, backed out of financing Osiris. So did the other three main partners, France, Italy and Belgium.

According to Marcello Coradini, secretary of ESA's Solar System working group, the SPC, which met last month to decide the that the new pressure on national agencies may allow for "imaginative solutions" to be found, while the US National Aeronautics and Space Administration (NASA) may also have some interest in participating.

But this latter possibility has touched on sensibilities about who might take the credit for photographs resulting from the mission. Some ESA officials, as well as members of the SPC, are worried that the space agency could lose important public

昏 relations opportunities by allowing non-member states to have large stakes in the camera.

Bonnet believes that, whatever agreement is reached, "ESA must control the public relations aspects". Coradini agrees. "In years to come, the public will not remember the isotopic composition of the comet, but everyone will remember the images."

A second option, which might be adopted if an agreement on a new call for proposals cannot be reached tomorrow, would be a limited upgrade to the navigational system, which could be achieved without raising the total cost of the mission.

But Horst Uwe Keller from the Max Planck Institute of Aeronomy in Lindau, principal investigator for Osiris, says this would be a "disaster" for the mission, as it would restrict imaging to the visible range.

Gernot Hartmann, head of the extraterrestrial science department of DARA, the German space agency, which would have shared the German contribution to Osiris with the Max Planck Society, declines to comment on reports that Germany is studying ways it might provide support for a fully European imaging system.

But he admits that he would find it "awkward" if the response to a new announcement of opportunity for the imaging system camera "was not clearly a European effort".

Alison Abbott
Although a previous announcement, only last year, failed to produce a viable proposal, Roger Bonnet, ESA's science director, says

\section{Cuts put standards at risk, say UK universities}

London. University vice-chancellors in Britain warned last week that standards in higher education could fall, following a 5 per cent reduction in their government funding for 1996/97. Some of the larger research universities have had to shoulder significant cuts to save smaller and newer institutions from unmanageable reductions in income.

Under the reductions, announced last week by the Higher Education Funding
Council for England (HEFCE), institutions such as the universities of Cambridge, Oxford and Imperial College, London, as well as some medical schools, will see their government funding cut by between 3 and 4.5 per cent. Funds for smaller universities and colleges, by contrast, will drop by between 1 and 2 per cent, while a few specialist institutions, such as the Wimbledon School of Art, will have their funds increased. 